\title{
Identifikasi Jenis Tumbuhan Obat di Kecamatan Doreng Kabupaten Sikka
}

\author{
Anastasia Nona Lelo, Mansur S \\ ${ }^{1}$ Program Studi Pendidikan Biologi, Fakultas Keguruan dan Ilmu Pendidikan, Universitas Nusa \\ Nipa, Maumere, 86111, Indonesia
}

Email: mansursaputra00@gmail.com

\begin{abstract}
Abstrak. Tujuan penelitian ini adalah untuk mengetahui jenis-jenis tumbuhan obat tradisonal yang ditemukan di Kecamatan Doreng Kabupaten Sikka. Pendekatan penelitian yang digunakan dalam penelitian ini adalah pendekatan kualitatif. Terdapat 21 jenis tumbuhan obat tradisional yang digunakan oleh hattra dalam menyembuhkan berbagai jenis penyakit. Dari 21 jenis tumbuhan tersebut ada 3 jenis tumbuhan obat yakni keru, padu api dan nitaruntarun yang tidak dapat dideskripsikan karena tumbuhan obat ini sangat langka. Jenis-jenis tumbuhan obat yang ditemukan di Kecamatan Doreng Kabupaten Sikka yaitu patikan kebo, jambu biji, jombang, tembeleken, susuruhan, tempuyung, awar-awar, prasman, rumput mutiara, bluntas, jambu, antana geude, daun jintan, leng-lengan, kumis kucing, tomat, daun sirih dan jarak merah.
\end{abstract}

Kata kunci: Identifikasi, Sikka, Tumbuhan Obat

\section{Pendahuluan}

Indonesia merupakan salah satu negara yang memiliki berbagai sumber daya alam yang melimpah baik sumber daya alam yang berada di darat maupun di laut. Potensi sumber daya alam di darat yang dimiliki Indonesia salah satunya adalah hutan. Hutan merupakan salah satu sumber daya alam yang memberi manfaat bagi manusia, baik ekologis maupun ekonomis. Sumber daya hutan terdiri dari dua bagian yaitu hasil hutan berupa kayu dan hasil hutan bukan kayu. Salah satu hasil hutan bukan kayu yang sering dimanfaatkan masyarakat di sekitar hutan adalah tumbuhan berkhasiat obat. Kekayaan alam hutan tropis Indonesia menyimpan berbagai tumbuhan yang berkhasiat sebagai obat dan dihuni oleh berbagai suku dengan pengetahuan pengobatan tradisional yang berbeda (Hariana, 2004). Luas kawasan mencapai 120,35 juta hektar sehingga Indonesia memiliki sekitar $80 \%$ dari total jenis tumbuhan yang berkhasiat obat (Heriyanto, dalam Kinho et al., 2011).

Tumbuhan obat merupakan tumbuhan yang mempunyai khasiat sebagai obat untuk menyembuhkan berbagai jenis penyakit, baik penyakit ringan maupun penyakit parah. Berdasarkan catatan WHO, IUCN dan WWF lebih dari 20.000 spesies tumbuhan obat yang digunakan $80 \%$ oleh penduduk seluruh dunia (WHO, 
2005). Tumbuhan obat ini setelah dipetik dan diracik, biasanya langsung dikonsumsi tanpa harus dicampur atau diolah dengan bahan-bahan kimia.

Tumbuhan obat sering ditemukan disekitar pekarangan rumah maupun di hutan. Dimana di Indonesia memiliki lebih dari 1.000 jenis tumbuhan yang dapat digunakan sebagai obat dan sekitar 300 jenis yang sudah dimanfaatkan untuk pengobatan tradisional. Oleh karena itu masih banyak tumbuhan obat yang belum diketahui atau diteliti tetapi sudah digunakan bertahun-tahun oleh nenek moyang kita sebagai tumbuhan obat. Nenek moyang menggunakan peralatan yang sederhana untuk mengolah tumbuhan obat.

Tumbuhan obat tradisonal yang digunakan untuk mengobati penyakit sudah diajarkan oleh generasi yang terdahulu ke generasi selanjutnya. Banyak masyarakat yang masih menggunakan tumbuhan obat tradisonal untuk pertolongan pertama saat sakit. Sebagian besar tumbuhan berkhasiat obat digunakan oleh masyarakat yang bertempat tinggal di pedesaan, terutama daerah yang belum terjangkau fasilitas kesehatan umum. Penduduk pedesaan di Indonesia khususnya yang bermukim disekitar kawasan hutan, seringkali menggunakan tanaman atau tumbuhan liar yang terdapat di hutan untuk pengobatan (Kusumawati, dalam Kinho et al., 2011).

Pemanfaatan tumbuhan berkhasiat obat atau herbal menjadi salah satu alternatif bagi masyarakat untuk mengobati suatu penyakit. Hal ini disebabkan karena penggunaan tumbuhan berkhasiat obat atau herbal disamping harganya yang cukup terjangkau juga tidak menimbulkan efek samping dibandingkan dengan menggunakan obat modern atau obatobatan dari bahan kimia. Selain itu tumbuhan obat ini juga dapat digunakan untuk semua jenis penyakit baik penyakit luar maupun penyakit dalam.

Tumbuhan obat sangat bermanfaat dan mempunyai banyak khasiat jika diolah dengan baik. Namun sekarang banyak masyarakat yang tidak mengetahui jenis tumbuhan obat yang sering digunakan oleh nenek moyang dahulu dan juga cara memanfaatkan tumbuhan obat tersebut dengan baik. Hal ini sesuai dengan hasil penelitian Sada dan Tanjung (2010) yang menyatakan bahwa, kendala yang dihadapi dalam pemanfaatan tumbuhan obat yaitu ketersediaan tumbuhan yang berkhasiat obat, karena sebagian besar tumbuhan yang dimanfaatkan merupakan tumbuhan liar dan belum dibudidayakan serta minimnya pengetahuan dari kaum muda tentang pemanfaatan dan pengelolahan tumbuhan obat. Hanya orang-orang tua dan orang yang diyakini masyarakat dapat meramu tumbuhan obat tersebut. Proses moderenisasi menyebabkan masyarakat untuk memilih pengobatan instan dan kadang-kadang tanpa resep dokter ke apotik membeli obat apabila sedang mengalami gangguan kesehatan dan tidak memikirkan efek 
samping mengkonsumsi obat kimiawi secara bebas terhadap organ-organ vital dalam tubuh seperti ginjal, jantung, hati, paru-paru.

Tumbuhan berkhasiat obat digunakan sebagai alternatif penyembuhan berbagai penyakit yang secara medis sulit ditangani dengan menggunakan obat sintetis. Hal ini karena efek jangka panjangnya dapat memberikan dampak yang kurang baik bagi organ tubuh lain yang tidak sakit sehingga penyakit tersebut menjadi bersifat lebih kompleks dari sebelumnya. Obat herbal atau obat yang menggunakan tumbuhan berkhasiat obat lebih aman dan juga memiliki khasiat yang sangat unik yaitu satu jenis tumbuhan dapat memiliki khasiat yang beragam.

Masyarakat di sekitar kawasan hutan yang kehidupannya sangat bergantung pada hutan, mengetahui pengetahuan tradisional dalam memanfaatkan tumbuhan atau bahan alami untuk pengobatan. Pengetahuan tentang tumbuhan obat, mulai dari

\section{Metode}

Pendekatan penelitian yang digunakan dalam penelitian ini adalah pendekatan kualitatif. Pendekatan kualitatif dilakukan pada kondisi alamiah, langsung ke sumber data dan peneliti adalah instrumen kunci. Data yang dimaksud dalam penelitian ini adalah data mengenai inventarisasi tumbuhan obat yang berada di Kecamatan Doreng. pengenalan jenis tumbuhan, bagian yang digunakan, cara pengolahan sampai dengan khasiat pengobatannya merupakan kemampuan alami dari masing-masing masyarakat disekitar hutan. Salah satu suku atau etnis yang masih memanfaatkan alam sekitar untuk kebutuhan hidupnya adalah masyarakat di Kecamatan Doreng.

Tumbuhan obat di Kecamatan Doreng sangat melimpah dan masyarakat di sekitarnya masih memanfaatkan untuk menyembuhkan berbagai jenis penyakit, termasuk penyakit yang sudah tidak bisa ditangani secara medis. Pemanfaatan tumbuhan sebagai obat sudah digunakan masyarakat secara turun temurun. Sebagian besar tanaman obat tersebut langsung diambil dari hutan atau kebun. Salah satu alasan masyarakat masih menggunakan tumbuhan obat tradisonal adalah karena tanpa efek samping dan bisa digunakan sebagai pertolongan pertama ketika sakit.

Teknik pengumpulan data ini merupakan langkah untuk mempermudah dalam mengkaji ataupun memperoleh informasi dari tumbuhan yang akan diteliti. Data dianalisis dengan cara melukiskan hasil penelitian dalam bentuk kata-kata atau kalimat. Dengan demikian penulis menguraikan secara mendalam hasil penelitian tersebut sesuai dengan keadaan yang sebenarnya yang terjadi 
di lapangan. Sugiyono (2016) mengemukakan bahwa, analisis data dalam penelitian kualitatif dapat dijelaskan dalam empat komponen yaitu, Data collection (pengumpulan Data), Data reduction (reduksi data), Data display (penyajian data), dan Conclusions drawing/verifying.

\section{Desain penelitian}

Pendekatan penelitian yang digunakan dalam penelitian ini adalah pendekatan kualitatif. Pendekatan kualitatif dilakukan pada kondisi alamiah, langsung ke sumber data dan peneliti adalah instrumen kunciProsedur Peneliitan

\section{Pengumpulan Data}

Data primer pada penelitian ini adalah data yang langsung dikumpulkan oleh peneliti di lapangan. Sumber data utama dalam penelitian kualitatif ialah kata-kata dan tindakan. Kata-kata dan tindakan merupakan sumber data yang diperoleh dari lapangan dengan mengamati atau mewawancarai. Peneliti menggunakan data ini untuk mendapatkan informasi langsung tentang jenis tumbuhan berkhasiat obat di Kecamatan Doreng

\section{Hasil dan Pembahasan}

Tumbuhan obat yang ditemukan di Kecamatan Doreng Kabupaten Sikka terdiri dari 21 jenis dan tumbuhan yang paling banyak digunakan adalah antana geudeu (puhe beta), jenis penyakit yang disembuhkan terdiri dari 22 jenis dan dengan mewawancarai bebearapa sumer data. Adapun yang menjadi sumber data primer dalam penelitian ini adalah dukun desa dan Masyarakat biasa di Kecamatan Doreng.

Data sekunder adalah data yang digunakan untuk mendukung pembahasan-pembahasan dalam penelitian ini. Data sekunder berupa profil desa dan foto-foto jenis tumbuhan yang biasa digunakan sebagai obat-obatan. Peneliti menggunakan data sekunder ini untuk memperkuat penemuan dan melengkapi informasi yang telah dikumpulkan melalui observasi, wawancara dan dokumentasi dengan hattra dan masyarakat biasa di Kecamatan Doreng.

\section{Analisis Data}

Analisis data dalam penelitian kualitatif dapat dijelaskan dalam empat komponen yaitu, Data collection (pengumpulan Data), Data reduction (reduksi data), Data display (penyajian data), dan Conclusions drawing/verifying.

penyakit yang paling banyak diobati adalah penyakit types dan diare, sedangkan bagian tumbuhan yang paling banyak digunakan adalah daunnya. 
Tabel 1. Jenis Tumbuhan Obat Tradisional di Kecamatan Doreng Kabupaten Sikka

\begin{tabular}{lllll}
\hline No & Nama Lokal & Nama Komersil & Nama llmiah & Famili \\
\hline 1. & Konjawa & Jambu biji & Psidium guajava & Myrtaceae \\
2. & Puhe beta & Antana geudeu & Centella asiatica L. & Apiaceae \\
3. & Wirohalan ro'un & Jombang & Taraxatum officinale L. & Asteraceae \\
4. & Ai bura & Susuruhan & Peperomia pellucida L. & Piperaceae \\
5. & Puhun warna & Tembeleken & Lantana camara L. & Verbenacrae \\
6. & Kligong & Tempuyung & Sonchus arvensis L. & Asteraceae \\
7. & Lupa uta & Awar-awar & Ficus septicum B. & Moraceae \\
8. & Bunga pagar & Prasman & Eupatorium triplinerve V. & Asteraceae \\
9. & Padu uter & Rumput mutiara & Hedyotis corymbosa L. & Rubiaceae \\
10. & Ai padu & Patikan kebo & Euphorbia hirta L. & Euphorbiaceae \\
11. & Beluntas & Beluntas & Pluchea indica L. & Asteraceae \\
12. & Manu waten & Daun Jintan & Coleus amboinicus L. & Lamiaceae \\
13. & Puhu bura & Leng-lengan & Leucas lavandulifolia Smith & Lamiaceae \\
14. & Kumis kucing & Kumis kucing & Orthosiphon stamineus Benth. & Lamiaceae \\
15. & Mu'u daha ro'un & Sembung & Blumea balsamifera L. & Astreaceae \\
& & & & \\
16. & Dagalait & Tomat & Solanum lycopersicum L. & Solanaceae \\
17. & Damar jawa & Jarak merah & Jotropha gossypifolia L. & Euphorbiaceae \\
18. & Ta'a ro'un & Daun sirih & Piper battle & Piperaceae \\
19. & Nitutraun ro'un & - & - & - \\
20. & Padu api & - & - & - \\
21. & Keru & - & - & - \\
\hline
\end{tabular}

\section{Bagian Tumbuhan yang Digunakan sebagai Obat}

Masyarakat di Kecematan Doreng Kabupaten Sikka menggunakan berbagai jenis bagian tumbuhan sebagai obat. Organ tumbuhan yang digunakan dalam pembuatan obat tradisional meliputi akar dan daun, batang, daun dan buah.

Jenis tumbuhan obat tradisional yang terdapat di Kecamatan Doreng Kabupaten Sikka 21 jenis tumbuhan obat tradisional yang digunakan oleh hattra dalam menyembuhkan berbagai jenis penyakit. Namun dari semua jenis tumbuhan tersebut ada tiga jenis tumbuhan obat yakni keru, padu api dan nitaruntarun yang tidak dapat dideskripsikan karena tumbuhan obat ini sangat langka. Sejalan dengan penelitian yang dilakukan oleh Abdullah et al., (2010) menyatakan bahwa, terdapat 17 jenis tanaman liar yang ditemukan, sekitar $76,5 \%$ (13 jenis) telah diketahui memiliki potensi untuk dimanfaatkan sebagai obat. Sedangkan penelitian yang dilakukan oleh Daniar et al., (2014) menyatakan bahwa, Berdasarkan hasil penelitian dapat disimpulkan bahwa telah ditemukan 90 jenis tumbuhan yang biasa digunakan sebagai obat alami oleh masyarakat Kecamatan Natar yang terdapat dilima Desa yaitu Pancasila, Sidosari, Brantiraya, Purwosari dan sukadamai. 


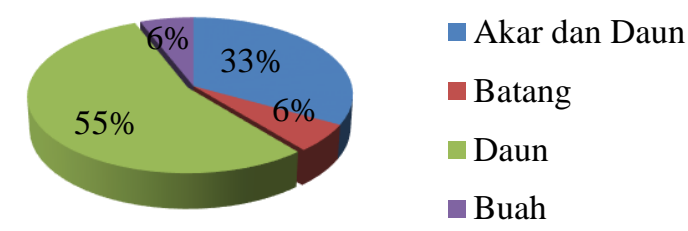

Gambar 1. Persentase Bagian Tumbuhan yang Digunakan Sebagai Obat di Kecamatan Doreng Kabupaten Sikka

Aminah et al., (2016) menyatakan bahwa, tumbuhan obat yang digunakan sebagian besar adalah untuk penyakit luar yaitu pada penyakit kulit dan demam, serta penyakit dalam seperti kencing manis, darah tinggi, penyakit kuning dan batuk darah. Pada penelitian Ardiansyah dan Rita (2019) melaporkan bahwa tumbuhan obat yang digunakan oleh warga Dusun Tompo Kecamatan Kempo yakni sebanyak 23 jenis, dan merupakan tumbuhan obat yang tidak umum digunakan oleh suku lain.

Tumbuhan obat sangat bermanfaat dan mempunyai banyak khasiat jika diolah dengan baik. Namun sekarang banyak masyarakat yang tidak mengetahui jenis tumbuhan obat yang sering digunakan oleh nenek moyang dahulu dan juga cara memanfaatkan tumbuhan obat tersebut dengan baik. Hal ini sesuai dengan hasil penelitian Sada dan Tanjung (2010) yang menyatakan bahwa, masalah/kendala yang dihadapi dalam pemanfaatan tumbuhan obat yaitu ketersediaan tumbuhan yang berkhasiat obat, karena sebagian besar tumbuhan yang dimanfaatkan merupakan tumbuhan liar dan belum dibudidayakan serta minimnya pengetahuan dari kaum muda tentang pemanfaatan dan pengelolahan tumbuhan obat. Hanya orang-orang tua dan orang yang diyakini masyarakat dapat meramu tumbuhan obat tersebut.

Masyarakat Kecamatan Doreng Kabupaten Sikka rata-rata memanfaatkan daun dengan cara direbus dan diminum airnya. Jumiarni dan Komalasari (2017) menjelaskan bahwa, organ tumbuhan yang digunakan sebagai obat meliputi seluruh bagian organ tumbuhan atau hanya salah satu bagian organ saja (akar, batang, daun, bunga, buah dan biji). Mereka melakukan cara ini agar zat-zat yang terkandung dalam daun pindah kedalam air, sehingga air yang diminum mengandung zat yang berguna dalam proses pengobatan. Daun yang digunakan dalam pengobatan ini adalah daun patikan kebo, daun jambu biji, daun jombang, daun tembeleken, daun susuruhan, daun tempuyung, daun awar-awar, daun prasman, daun rumput mutiara, daun bluntas, daun antana geude, daun jintan, daun leng-lengan, dan daun 
kumis kucing. Sedangkan organ tumbuhan yang paling sedikit digunakan adalah buah dan batang yakni masing-masing $6 \%$.

Buah merupakan organ pada tumbuhan berbunga yang merupakan perkembangan lanjutan dari bakal buah yang membungkus dan melindungi biji sedangkan batang merupakan salah satu dari organ tumbuhan dan merupakan sumbu tumbuhan tempat semua organ lain bertumpu dan tumbuh. Batang tumbuhan mengandung lignin (zat kayu) yang menghasilkan senyawa kimia aromatis berupa fenol dan kresol. Buah dan batang yang digunakan oleh masyarakat Kecamatan Doreng Kabupaten Sikka sebagai obat tradisional adalah buah tomat dan batang jarak merah.

Akar merupakan bagian tumbuhan yang berfungsi untuk menyerap air dan zat-zat mineral yang terkandung dalam tanah dan sebagai tempat penimbun cadangan makanan. Akar tumbuhan mengandung borneol, cineole, limonene. Akar tumbuhan yang biasa digunakan oleh masyarakat

\section{Kesimpulan}

Jenis-jenis tumbuhan obat yang ditemukan di Kecamatan Doreng Kabupaten Sikka yaitu patikan kebo, jambu biji, jombang, tembeleken, susuruhan, tempuyung, awar-awar, prasman, rumput mutiara, bluntas, jambu, antana geude, daun jintan, lenglengan, kumis kucing, tomat, daun sirih dan jarak merah.
Kecamatan Doreng Kabupaten Sikka sebagai obat adalah akar patikan kebo, akar jombang, akar tempuyung, akar antana geude dan akar daun jintan. Rizal dan triana (2019) menjelaskan hasil penelitiannya yaitu, jenis tumbuhan obat yang dimanfaatkan sebagai bahan baku berkhasiat obat tradisional kelas monocotyledoneae dan dicotyledoneae yaitu daun, batang, akar/rimpang, buah, biji, bunga, kulit, dan getah, dengan khasiat yang beranekaragam.

Penelitian Ardiansyah dan Rita (2019) menjelaskan Bagian yang digunakan beranekaragam, baik berupa akar, kulit batang, daun, buah, maupun getah. Sedangkan Mulyani et al., (2020) menyatakan bahwa masyarakat di Kecamatan Dawuan dinilai baik terkait pengetahuan obat dan bernilai sangat baik terkait pemanfaatantanaman obat menggunakan bagian tumbuhan seperti daun, batang, bunga, biji, buah, akar, rimpang, getah dan seluruh bagian untuk memelihara kesehatandan menyembuhkan penyakit.

Organ tumbuhan yang digunakan sebagai obat oleh masyarakat Kecamatan Doreng Kabupaten Sikka yaitu akar, batang, daun dan buah. Organ tumbuhan yang paling banyak digunakan adalah daun sebanyak $55 \%$ dan yang paling sedikit adalah batang $5 \%$ dan buah $5 \%$ sedangkan akar dan batang $33 \%$. 


\section{Daftar Pustaka}

1. Abdullah, M., Mustikaningtyas, D. dan Widiatningrum, T. 2010. Inventarisasi JenisJenis Tumbuhan Berkhasiat Obat Di Hutan Hujan Dataran Rendah Desa Nyamplung Pulau Karimunjawa. Jurnal Biosaintifika. Vol 2 (2) : 75-81.

2. Ardiansyah dan Rita. R. R. N. D 2019. Identifikasi Tumbuhan Obat di Zona Khusus Taman Nasional Gunung Tambora Kabupaten Dompu. JurnalSilva Samalas. Vol. 2. No. 2: $99-108$

3. Aminah, S.,Wardenaar E., dan Muflihati. 2016. Tumbuhan Obat Yang Dimanfaatkan Oleh Battra Di Desa Sejahtera Kecamatan Sukadana Kabupaten Kayong Utara. Jurnal Hutan Lestari. Vol 4 (3) : $299-305$.

4. Daniar. R., Yulianty., dan Lande. M. L. 2014. Inventarisasi Tumbuhan Yang Berpotensi Sebagai Tumbuhan Obat Alami Di Kecamatan Natar Kabupaten Lampung Selatan. Prosiding Seminar Nasional. Hal. 324-331

5. Jumiarni, W.O., dan Komalasari. 2017. Eksplorasi Jenis dan Pemanfaatan Tumbuhan Obat Pada Masyarakat Suku Muna di Permukiman Kota Wuna. Trad. Med. J., January. Vol. 22 (1) : 45-56.

6. Kinho, J., Arini, D.I.D., Halawane, J., Nurani, L., Halidah, Kafiar, Y., dan Karundeng, M.C. 2011. Tumbuhan Obat Tradisional di Sulawesi Utara Jilid II. Balai Penelitian Kehutanan: Manado.

7. Mulyani. Y., Sumarna. R., Patonah. 2020. Kajian Etnofarmakologi Pemanfaatan Tanaman Obat Oleh Masyarakat Di Kecamatan Dawuan Kabupaten Subang Provinsi Jawa Barat. Jurnal Farmasi Galenika (Galenika Journal of Pharmacy). Vol.6. No. 1: 3754. Doi: https://doi.org/10.22487/j24428744..v.i.13572

8. Rizal. S dan Triana. S. 2019. Inventarisasi Dan Identifikasi Tanaman Bekhasiat Obat Di Kabupaten Musi Banyuasin Sumatera Selatan. Indobiosains. Vol. 1. No. 2: 50-62. Doi: http://dx.doi.org/10.31851/indobiosains.v1i2.3199

9. Sada, J.T., dan Tanjung, R.H.R. 2010. Keragaman Tumbuhan Obat Tradisional di Kampung Nansfori Distrik Supiori Utara, Kabupaten Supiori Papua. Jurnal Biologi Papua. Vol 2 (2) : 39-46.

10. Sugiyono. 2016. Metode Penelitian. Penerbit Alfabeta: Bandung.

11. WHO. (2005). Review of Traditional Medicine in the South-East Asia Region. 